\title{
Feasibility Study on the Image Positioning of Cruise Tourism in Tianjin
}

\author{
Xiaonan $\mathrm{Li}$ \\ No.8, Yashen Raod, Jinnan District, Tianjin City, China \\ lily2019151412@163.com
}

Keywords: Cruise; Tourism image; Image positioning; Feasibility study

\begin{abstract}
The prosperous development of cruise tourism makes Tianjin plays a very important role in the national cruise market, and as the joint development of Beijing, Tianjin and Hebei has improved into a national strategy, Tianjin is expected to become the capital of cruise in north China, creating the position of cruise tourism image. This paper uses the SWOT analysis to analyze the image positioning of cruise tourism in Tianjin and proposes corresponding countermeasures.
\end{abstract}

\section{Introduction}

Cruise tourism in Tianjin has officially entered the period of vigorous development. In 2007, Italy Costa Cruise Lines' "Allegra" cruise expanded the first cruise route from Tianjin to Japan and Korea with Tianjin as the home port, opening the cruise tourism market in Tianjin. In 2010, Asia's largest cruise home port - Tianjin International Cruise Home Port was established, opening the prelude to the rapid development of Tianjin's cruise tourism. In 2013, the National Tourism Administration approved the establishment of China's cruise tourism development experimental zone in Tianjin Binhai New Zone, indicating that Tianjin's international cruise tourism was included to national development strategies and the cruise industry had entered a new period of innovative development, leading development and integrating development. In 2015, Tianjin cruise home port extended its season to December for the first time, and started the winter operation of Tianjin cruise home port. With the challenges brought by the establishment of Tianjin free-trade zone and the startup of the "air-bridge service" mode, the amount of voyage and tourists in Tianjin home port exceeded the past in 2015, reaching the highest. According to statistics, Tianjin International Cruise home port received a total of 96 international cruise ships, an increase of $74.5 \%$; the total number of tourists was 431,000 , an increase of $93 \%$. It is expected that in 2016, there will be more than 100 ships at Tianjin cruise home port for the first time.

\section{Current Status of Tianjin's Tourism Image Positioning}

Tourism Image Positioning of a City. Tourism image of a city is people's overall, abstract and general understanding and evaluation of a city as well as a rational synthesized impression of a city's history, reality and future beliefs. It includes not only tourists' experience of a city's overall environment, attractions, resident quality and folk customs, but also the internal quality of a city, such as operation management, economic development, urban culture and development prospect, etc. Tourism image positioning renders direction for image design and is the premise for designing image of tourism destinations. Reasonable and appropriate tourism image positioning cannot only make tourism destinations maintain the characteristics in the fierce competition and give tourists a clear and distinctive perception of the tourism destination, but can also guide local government and local tourism investment. Therefore, urban tourism image positioning is essentially the process to determine a city's tourism development direction and construction goals based on judging the characteristics of a city's tourism.

Current Status of Tianjin's Tourism Image Positioning. With a history of six hundred years, Tianjin has rich and colorful tourism resources, including not only ancient towns and humanistic and historical sites, but also modern constructions and natural resources. Its famous tourist attractions 
include: Great Wall in north Ji County - Huangxia Fort, Gousse Haimen Dagu Fort ruins, three mountain tourist area Muyu, put water Xia - the Haihe River scenery etc. Also reflect the historical and cultural resources: Thean Hou Temple, alongside Fujian and Taiwan Futian Mazu temple for three Chinese Pak Chaotiangong Boyle, "International Architecture Exhibition" is called the five Avenue street, and the mansion, Huo Yuanjia hall, Yuan Shikai, and Zhang Xueliang dated Cao Yu and other celebrities live etc. The folk art Yangliuqing, clay Zhang Caisu, Weiji kites are well-known Tianjin folk arts and crafts. Also cannot be mentioned is a very Tianjin characteristics of comic sketches, loved by the people of the country. The Goubuli, Guifa Xiang twist, erduoyan, the cat does not smell dumplings known throughout the country has so many resources, Tianjin tourism will also usher in a glorious period.

As one of China's four municipalities directly under the central government, and combined with its own resources, Tianjin proposes the "take a glimpse of Tianjin to get to know contemporary China" image positioning. In recent years, with the coordinated development of Beijing, Tianjin and Hebei's tourism, Tianjin's tourism has entered a stage of leaping development. "take a glimpse of Tianjin to get to know contemporary China", the world's cultural heritage, Tianjin folk culture, coastal leisure, mountains and historic sites... numerous brilliant tourism name cards have attracted a lot of domestic and foreign visitors, and Tianjin has become a top choice of tourism for tourists from Beijing and Hebei.

\section{Analysis of the Strengths of the Image Positioning of Cruise Tourism in Tianjin}

Superior Geographical Location and Location Conditions. Tianjin is the biggest coastal city in north China opened to the outside world located in the downstream of the North China plain northeast of the Haihe River Basin, east of Bohai, north of Yanshan, west of the capital city of Beijing, is the five major tributaries of the Haihe River and the confluence of the estuary, known as the "nine under the river" and "river hub". Tianjin is 120 kilometers away from Beijing, and has always been the point guard Gyeonggi and portal. Tianjin location advantages, located in the central China north of Gold Coast, not only to capital, or large areas of the north and northwest of the North Sea, is the center China open two sector of the Eurasian Continental Bridge is Chinese within the shortest distance eastern starting point. Tianjin port is the largest comprehensive trade port in North China, with the largest container port in the country, with more than and 300 ports in more than and 170 countries and regions in the world.

The First Cruise Home Port in North China and Also the Biggest Cruise Home Port in Asia is Established in Tianjin. Tianjin international cruise home port area is located in the southern tip of Tianjin Dongjiang port, put into use in June 26, 2010, shoreline length of 1600 meters, 6 layout and function of cruise berths, is Asia's largest cruise home port design scale. The development of an area of 700 thousand square meters, has been completed and put into operation the shoreline length of 625 meters, can be parked at the same time 2 large cruise ships; depth of -11.5 meters, can accommodate the world's largest luxury cruise ships; passenger terminal building area of 59 thousand square meters, while 4000 people provide immigration clearance services, designed annual passenger clearance the capacity of 500 thousand passengers. In order to adapt to the development of cruise home port, Tianjin cruise home port planning and construction of the two phase of the project, the foundation area of 112 thousand and 100 square meters, the new coastline of 442 meters, can accommodate more intensive cruise berthing operation. The June 2014 Tianjin international cruise home port two terminal has been built, the design capacity of 1 million passengers, while the actual reception capacity is greater than 1 million. In order to meet more and more international luxury cruise, Tianjin international cruise home port company launched a comprehensive international cruise terminal second boarding bridge project, the whole project has been completed into the trial operation stage. Second boarding bridge put into use can solve the problem of the company at present two cruise berth, in order to adapt to the development trend of international cruise port of large-scale, intensive, comfortable, convenient and efficient customs clearance services for Chinese and foreign tourists. 


\section{Analysis of Weakness to Tianjin Cruise Tourism Image Positioning}

Tianjin's Cruise Tourism Resources Cannot Retain Visitors. Tianjin has rich tourism resources, but its reputation in the international market is relatively low. Especially, compared with its neighboring Beijing, although cruises stop at Tianjin International Cruise Home Port, most visitors will choose to visit Beijing, and Tianjin is more used as the external port of Beijing, which is related to Beijing's powerful international influence on one hand, and on the other hand, it is also related to Tianjin's lack of tourism resources to attract cruise visitors.

Tianjin Cruise Tourism has Short Season and is Greatly Influenced by Seasons and Climate. Located in the north, Tianjin International Cruise Home Port is subject to the influence of climate and the cruise itself. Ever since the port was opened, the home port is only opened in summer from every June to September, lasting for 4 months. As it is cold in the winter, there is nearly no home port route. In recent years, as the northern cruise tourism market continues to heat up, cruise companies are also extending the shipping seasons, but only to October. In 2015, Tianjin Cruise Home Port first extended the shipping season to December and started the winter operation. On December 28, 2015, as more than 1200 visitors returned with the Costa's "The Atlantic" started from Tianjin port, the operation of Tianjin Cruise Home Port routes in 2016 was officially started, not only realizing the breakthrough of cross-year operation of cruise routes for Tianjin port for the first time, but also breaking the previous practice of starting routes in June.

\section{Analysis of Opportunities to Tianjin Cruise Tourism Image Positioning}

National and Tianjin Municipal Policy Support and Guarantee. On April 4, 2013, the National Tourism Administration officially approved to establish experimental zone at Tianjin Binhai New Zone for the development of China's cruise tourism and include Tianjin international cruise tourism into national development strategies. Later on, Tianjin government promulgated the "Three-Year Plan of Action for the Establishment of Experimental Zone for China's Cruise Tourism Development (2015-2017)", and proposed to actively gain for various national policy supports to promote the rapid development of the cruise industry. Especially, in terms of clearance, promote relevant departments to realize quick check and pass to save time for tourists.

On January 1, 2015, the Chinese government established free-trade, and as China's only cruise home port in free-trade zone, Tianjin port faced a new opportunity. The target of developing cruise home port is to promote the development of the entire industry chain. Policy advantages may extend the subsequent industrial chains of cruise companies, including providing more convenience for cruise supplies, and international material transit.

Integrated Development of Beijing, Tianjin and Hebei. Tianjin will reply on the integration of Beijing, Tianjin and Hebei to develop cruise tourism, which is demonstrated in two specific aspects: one is the target customer market. Tianjin will reply on the huge customer market of dozens of inland provinces and cities in north China. Especially, in a short period, in addition to Beijing and Tianjin, Hebei, Shandong, Liaoning, Jilin and other neighboring customer markets have huge development potential. The other is the cruise tourism resources. Tianjin will reply on China's political center, economic center, cultural center and international exchange center Beijing to attract international tourists.

\section{Analysis of Threats to Tianjin Cruise Tourism Image Positioning}

Rapid Development of Surrounding Cruise Home Port. In April 2015, the Ministry of Transport accounted the "National Coastal Cruise Port Layout Plan", planning to set 12 ports of departure, including Dalian International Cruise Home Port, Qingdao International Cruise Home Port and Yantai International Cruise Home Port in north China. The establishment and usage of these cruise home ports make the competition between cruise ports in north China become increasingly fierce, and Tianjin International Cruise Home Port is no longer the only home port in north China. 
Single Cruise Destinations. Due to the influence of various factors such as geographical location and vacation system, voyage routes starting from Tianjin International Cruise Home Port usually take Japan and Korea as the destinations, thus the destinations are very single unlike cruise home port in Shanghai and Xiamen where there are rich cruise routes, including not only routes to Japan and Korea to the north, but also Vietnam and Singapore to the south.

\section{Measures for Cruise Tourism Image Positioning in Tianjin}

Create the "Capital of Cruise" by Taking Advantage of Favorable Location. The cruise market in north China has huge potential. As the synergetic development of Beijing, Tianjin and Hebei has improved into a national strategy, Tianjin, as the center of circum Boihai-Sea economic zone and an important port city in north China enjoying advantageous conditions to carry out cruise tourism, has already become an important port for each international cruise company to develop Asia routes. With such advantageous geographic location, Tianjin can be well created into the "capital of cruise" in north China.

Complement with the "Take a Glimpse of Tianjin to Get to Know Contemporary China" Tourism Image. A city's tourism resources should be taken into full consideration in positioning its tourism. It is undeniable that the most representative tourism resource in Tianjin is various styles of buildings constructed during the foreign settlement. Therefore, in image positioning, "capital of cruise" can be organically combined with "take a glimpse of Tianjin to get to know contemporary China" while complementing each other to form the overall image positioning of "take a glimpse of Tianjin to get to know contemporary China and take cruise at contemporary Tianjin".

Promote Cruise Tourism Image with Multiple Platforms. In order to further improve the influence and reputation of Tianjin's cruise tourism image, a series of new measures to publicize marketing and serve for tourists have been proposed against the background of Internet + . The publicity channels are greatly expanded through establishing network and new media platform, and multilingual Tianjin tourism information network and microblog, WeChat, $\mathrm{O} 2 \mathrm{O}$ e-commerce platform, Facebook, Twitter and various other new media platforms are used for comprehensive promotion of Tianjin's cruise tourism image from brand packaging, image publicity, activity planning and market expansion so as to promote Tianjin cruise tourism brand to become bigger and stronger and create a new tourism image of Tianjin.

\section{Conclusion}

Tianjin occupies an important position in the cruise market in north China. It can be seen from analysis that Tianjin is fully equipped with the conditions of cruise tourism image positioning, so this great opportunity of developing cruise tourism can be used to create Tianjin into the "Capital of Cruise" in north China, forming organic combination with the "take a glimpse of Tianjin to get to know contemporary China" while complementing each other to construct the overall image positioning of "take a glimpse of Tianjin to get to know contemporary China and take cruise at contemporary Tianjin”.

\section{References}

[1] X.N.Li: Journal of Jiamusi Education Institute,(2014)No.6,p.281-304.(In Chinese)

[2] Y.Wang,Y.X.Zhang and L.Li: Journal of Hainan Radio\&TV University,(2014)No.4,p.72-78.(In Chinese)

[3] X.N.Li: Economic Research Guide,(2013)No.6,p.204-205.(In Chinese)

[4] Q.S.Wang and Q.Yang: Journal of Tianjin University of Commerce,(2013)No.3,p.41-46.(In Chinese) 
[5] J.M.Cong: The Development Strategy Research of China Cruise Tourism Based on the SWOT Analysis(M.B.A.,Dalian Maritime University,China,2012),p.58-60.(In Chinese)

[6] Q.S.Wang: Economic Research Guide,(2011)No.3,p.169-170.(In Chinese)

[7] http://www.tjtour.cn

[8] http://www.ccyia.com

[9] http://www.cnta.gov.cn

[10] http://www.tjlyrcw.com 